Article

\title{
Factors Affecting Intention to Adopt Cloud-Based ERP from a Comprehensive Approach
}

\author{
Byungchan Ahn and Hyunchul Ahn *(i) \\ Graduate School of Business IT, Kookmin University, 77 Jeongneung-ro, Seongbuk-gu, Seoul 02707, Korea; \\ bob97kr@kookmin.ac.kr \\ * Correspondence: hcahn@kookmin.ac.kr; Tel.: +822-910-4577
}

Received: 14 July 2020; Accepted: 3 August 2020; Published: 10 August 2020

check for updates

\begin{abstract}
To enhance the sustainability of business operations, enterprises have interests in enterprise resource planning (ERP) transitions from an existing on-premise method to a cloud-based system. This study conducts a comprehensive analysis using the technology-organization-environment, diffusion of innovation, and the model of innovation resistance frameworks. The empirical analysis shows that the factors of organizational culture, regulatory environment, relative advantage, trialability, and vendor lock-in all had a significant influence on the intention to adopt cloud-based ERP, while information and communications technology skill, complexity, observability, data security, and customization had no significant influence on the intention to adopt cloud-based ERP. This study's findings provide meaningful guidance for companies that want to adopt cloud-based ERP, governments that support enterprise digitalization, and vendors who sell cloud-based ERP systems.
\end{abstract}

Keywords: cloud ERP; technology-organization-environment; innovation; resistance; adoption

\section{Introduction}

Most large enterprises stopped introducing new enterprise resource planning (ERP) systems in around 2010. Usually, companies decide every 10 years whether or not to rebuild their ERP. Considering this cycle, the market demand for advanced ERP is expected to erupt, either later this year or early next year. The most important factor to consider in advanced ERP is the response to the advent of cloud technology. Existing ERP established itself as a system that integrates and manages a company's overall business processes. However, recently, since it is combined with the latest technologies such as machine learning, analysis, and the cloud, advanced ERP is garnering attention as a core system that can help executives make more informed and rapid decisions. In addition, Systems, Applications \& Products in Data Processing (SAP), a major German ERP package provider, said it would discontinue technical support for existing ECC 6.0 products in 2025 and is strongly driving the transition to the S/4 HANA cloud. Oracle and Microsoft are also insisting on a cloud-first policy. So, existing on-premise ERP users are being forced to switch to cloud-based ERP. However, no matter how good a cloud-based ERP system is, if an organization's decision-makers and stakeholders do not intend to adopt it, then doing so would not contribute to improving the organization's productivity or maintaining its sustainability.

According to Gartner, the ERP market has been undergoing a generational technology shift, due to the advent of cloud computing technology [1]. Due to the benefits of moving away from on-premise ERPs, especially in managing upgrades and maintenance processes, cloud-based ERP emerged in the mid-2000s [2]. While most cloud-based ERPs are provided to customers as software as a service (SaaS), a number of ERP platforms as a service (PaaS) also exist [3,4]. Gartner predicts that almost 32\% of large enterprises with ERP systems up for replacement might replace their on-premise ERP with the SaaS service model by 2021 [1]. It is clear that the cloud-based ERP market is growing. 
In particular, as coronavirus disease 2019 (COVID-19) spread in early 2020, the sustainability of corporate information systems of companies became a very important topic of corporate management. Interlocked with the topic of sustainability, cloud-based ERP is becoming increasingly important. Companies that have adopted cloud-based ERP are much better at working from home, and therefore ahead in maintaining continuity during the COVID-19 pandemic crisis. Therefore, interest in the adoption or acceptance of cloud-based ERP has become important at this time.

As a result, research on cloud-based ERP has been rapidly increasing over recent years. In particular, studies on affecting the adoption of cloud-based ERP have been recently released, and many such studies are based on the technology-organization-environment (TOE) framework, Ddiffusion of innovation (DOI) theory, or the model of innovation resistance (MIR). So far, cloud-based ERP adoption has been analyzed in terms of TOE [5-15], DOI [16-20], and MIR [21-23]. TOE-centered research has the advantage of approaching ERP from a comprehensive point of view, but it cannot reflect the innovation characteristics of new technology, like cloud-based ERP. The introduction of the DOI perspective might reflect the innovation characteristics of the technology itself, as indicated above, but this only considers the new technology as a positive facilitator, and does not reflect its resistance factors. Therefore, only by adding the MIR perspective to the above two perspectives can a truly comprehensive view be achieved.

With this background, this study intends to provide insights into what factors should be considered regarding the adoption of cloud-based ERP. Based on the TOE, DOI, and MIR frameworks, a research model was developed to identify influential factors on intention to adopt cloud-based ERP. Specifically, a total of 10 characteristics are analyzed by classifying cloud-based ERP preference characteristics (i.e., information and communications technology (ICT) skill, organizational culture, regulatory environment, relative advantage, complexity, trialability, and observability) and resistance characteristics (i.e., data security, vendor lock-in, and customization) for this study.

\section{Theoretical Background}

\subsection{Cloud-Based ERP and On-Premise ERP}

A cloud-based ERP is a cloud computing environment. It is invisible like a cloud, but the ERP package is run under a computing resource that exists in something on the Internet [24-26]. On the other hand, an on-premise ERP is directly installed on to one or more physical servers. Therefore, it requires hardware, a software environment, and personnel [26]. ERP packages as infrastructure as a service (IaaS) are also used, as well as PaaS or SaaS ERP packages, which are run in large part or entirely by the ERP package provider. The main benefit of a cloud-based ERP as opposed to an on-premise ERP is that it minimizes the cost of access and requires less information technology (IT) support and maintenance. Access to reliable information, avoiding the duplication of data in the database, reduction of adoption and cycle time, cost savings, improved scalability, and less maintenance are some of the other benefits of implementing a cloud-based ERP [27]. The advantages of a cloud-based ERP include cost savings, initial introduction cost, manpower cost, usability, efficiency, scalability, and flexibility; whereas ease of control is the main advantage of on-premise ERP [26].

With the continuous development of cloud computing technology, cloud-based ERP has been developed as an alternative to the on-premise solution. According to Grabski et al. [28], cloud computing can fundamentally change the ERP environment. The data and the application are no longer on the premises of a company. Rather, a provider offers access to the application that can be adapted to the needs of the user and hosts the data securely on the Internet. Many research questions are related to this evolutionary method of ERP system. Arnesen ([29], p. 47) added that "As the market shifts to cloud environments, ERP vendors are developing hosting or cloud solutions". According to Mezghani ([30], p. 47), "Cloud-based ERP appears to have become a real alternative to on-premises ERP, and companies are likely to push for cloud solutions". A recent study examined the hidden link between one of the key pillars of Industry 4.0 (e.g., cloud-based ERP) and the attributes of sustainable corporate performance, 
considering the impact of variables such as company size, cloud service type and possible offers used as control variables and achieve sustainable performance at the same time [31].

\subsection{Cloud-Based ERP Adoption}

From a comprehensive review of the literature, Ngai et al. ([32], p. 1) identified 18 critical success factors (CSF), including more than 80 sub-elements, of ERP adoption by an organization. Among the 18 CSFs, the two most frequently mentioned in reference to ERP system adoption are "training and education" and "top management support". According to Bhaaradwaj and Lal [33], several factors, such as organizational attitude, credibility, apparent ease of use, and relative advantage towards technology influence an organization's decision to adopt cloud computing. Bellamy [34] discovered that lack of skilled labor, data security risks, and high cost are the main reasons why organizations hesitate to adopt cloud-based services. Kinuthia [5] believed that compatibility, competitive pressure, employee IT expertise, business size, and cost are the key factors to consider when adopting a cloud-based ERP.

In Table 1, which summarizes the research on cloud-based ERP adoption, it is evident that a number of studies have been done on the benefits and challenges of cloud-based ERP, framework development for cloud-based ERP, and the factors affecting providers' cloud-based ERP implementation perspective. However, from the perspective of an enterprise or organization, only limited research has been conducted that has played an important role in cloud-based ERP adoption by organizations. Most recent studies have been conducted only in the context of developed countries. Peng and Gala [21] identified the benefits of, and barriers to, cloud-based ERP adoption, articulating system speed and performance, ERP cost and support, ERP mobility, and system upgrade and enhancement as benefits, while highlighting organizational challenges, vendor lock-in, data security, transparency and data privacy, and integration difficulties as barriers.

Recently, Adnan AlBar and Md. Hoque [6] studied the factors affecting cloud-based ERP adoption in Saudi Arabia, and Moh'd Anwer Al-Shboul [7] sought a better understanding of the logistical factors of cloud-based ERP adoption by small and medium enterprises (SMEs) in developing economies. There have been studies conducted in Europe, South Africa, Egypt, and Taiwan. Yu-Wei Chang [35] explored the enablers and inhibitors that drive organizations to switch to cloud-based ERP systems. EPR packages are mainly used in Korea and Japan in Asia, while few studies have been conducted in Korea or Japan.

Table 1. Literature review on cloud-based enterprise resource planning (ERP) adoption.

\begin{tabular}{ccc}
\hline Framework/Sample & Findings & Reference \\
\hline Semi-Structured Interviews/Six companies & $\begin{array}{c}\text { This study identified the potential security issues caused } \\
\text { by the deployment of cloud-based ERP systems from the } \\
\text { perspective of the provider. }\end{array}$ & [36] \\
\hline Interviews/16 IT consultants & $\begin{array}{c}\text { The study identified cloud-based ERP benefits and barriers } \\
\text { to cloud-based ERP adoption, highlighting vendor lock-in, } \\
\text { data security, and integration difficulties as barriers. }\end{array}$ & [21] \\
\hline $\begin{array}{c}\text { Survey/637 American IT security } \\
\text { practitioners }\end{array}$ & $\begin{array}{c}\text { This study found that cloud-based ERPs ensure data } \\
\text { security, Internet accessibility, and business profit at a } \\
\text { minimum cost in business organizations. }\end{array}$ & [37] \\
\hline $\begin{array}{c}\text { Interviews/Three companies } \\
\begin{array}{c}\text { Online survey/136 } \\
\text { Quantitative method with UTAUT2 } \\
\text { TOE, DOI }\end{array}\end{array}$ & $\begin{array}{c}\text { This study developed a framework that explains how small } \\
\text { and large businesses are associated with the opportunities } \\
\text { and concerns identified in adopting cloud-based ERP. }\end{array}$ & [38] \\
\hline $\begin{array}{c}\text { This study found that the TOE and DOI factors were } \\
\text { strongly related to cloud-based ERP adoption. }\end{array}$ & [6] \\
\hline $\begin{array}{c}\text { Habits and behavioral intentions have a significant impact } \\
\text { on users of systems that adopt and use cloud-based ERP in } \\
\text { large Indonesian companies. }\end{array}$ & [39] \\
\hline
\end{tabular}


Table 1. Cont.

\begin{tabular}{ccc}
\hline Framework/Sample & Findings & Reference \\
\hline $\begin{array}{c}\text { TOE framework/131 respondents in SMEs } \\
\text { in developing economies (Bahrain, Egypt, } \\
\begin{array}{c}\text { Emirates, Jordan, Kuwait, Lebanon, Oman, } \\
\text { Qatar, Saudi Arabia, and Turkey) }\end{array}\end{array}$ & $\begin{array}{c}\text { Competitive pressure, high-level management support, } \\
\text { enterprise readiness, enterprise size, technological } \\
\text { readiness, and technical barriers have a major impact on } \\
\text { the adoption of cloud-based ERP. }\end{array}$ & {$[7]$} \\
\hline $\begin{array}{c}\text { Survey/212 participants in Taiwan, TOE, } \\
\text { ECT (Expectation confirmation theory), } \\
\text { Two-factor theory }\end{array}$ & $\begin{array}{c}\text { Technology (system quality), organization (financial } \\
\text { advantage), and environment (industry pressure) contexts } \\
\text { are identified to be the prerequisites of switching benefits. } \\
\text { The perceived risk of a cloud-based ERP system, as well as } \\
\text { the satisfaction and use scope of an existing ERP system, can } \\
\text { be regarded as a predictive indicator of conversion costs. }\end{array}$ & [35] \\
\hline
\end{tabular}

\subsection{Technology-Organization-Environment (TOE) Framework}

The TOE framework was developed for exploring the adoption of technology by Tornatzky and Fleischer [40]. The framework examines three important factors that influence the adoption of new technologies: technology, organization, and environment [41]. The TOE framework has been widely utilized to research the adoption of cloud-based ERP [5-15] and cloud computing [42]. Juiz et al. [43] used the TOE framework for SaaS ERP adoption by SMEs, and explored perceived value, security concerns, configurability and customization, organizational readiness, top management, competitive pressure, and vendor qualities. Qian et al. [12] collected 102 valid data records from the manufacturing and service sector and developed a theoretical model using the TOE framework, to discover the fact that the top management support factor significantly and positively correlated with the intention to adopt cloud-based ERP systems by manufacturing SMEs in Malaysia.

AL-Shboul [7] examined cloud-based ERP adoption based on the TOE framework and identified competitive pressure, top management support, enterprise readiness, enterprise size, technological readiness, and technical barriers as factors that exerted a significant influence on cloud-based ERP adoption. AlBar and Hoque [6] also investigated cloud-based ERP adoption intention based on the TOE framework, and found that ICT skill, ICT infrastructure, top management support, regulatory environment, and competitive environment were significantly related to cloud-based ERP adoption, while organizational culture was not significantly related. Yu-Wei Chang [35] studied cloud-based ERP switching intention using the TOE framework, and discovered that financial advantage, system quality, and industry pressure were significantly related to cloud-based ERP switching intention, while information quality and government support were not significantly related.

\subsection{The Diffusion of Innovation (DOI) Theory}

Innovation was defined by Rogers as "an idea, practice, or object that is perceived as new by an individual or other unit of adoption" ([44], p. 11). The DOI theory proposes that five innovative features affect the IT adoption intention. These five characteristics are believed to play an important role in helping businesses embrace new innovative technologies (e.g., cloud-based ERP) [6].

Tornatzky and Kelin [45] revealed that one of the most extensive research and innovation features that determines the IT adoption rate-including the enterprise-level cloud-based ERP adoption rateis a relative advantage. Most companies believe that cloud-based ERP saves time and money, promotes communication, and leads to more efficient collaboration of new business applications, as compared with traditional ERP systems, so that they are interested in adopting cloud-based ERP [16]. According to Premkumar [17], compatibility is identified as one of the most important components of innovation adoption using information systems. However, more complicated company innovation processes are controversial. Complexity is the main barrier to a rapid pace of technology adoption [18].

Meanwhile, observability and trialability are important factors that influence the implementation of innovative IT, such as cloud-based ERP [19]. Jeyaraj et al. [20] revealed that these two innovation characteristics significantly impact ICT adoption such as cloud-based ERP. Lim [24] studied characteristics 
of innovation as the introductory characteristics of cloud computing services with relative advantage, complexity, suitability, cost reduction, attemptability, and observability. Shin [46] defined relative advantage, suitability, and complexity as the innovation characteristics of cloud computing services, and explored various factors, such as psychological factors, innovation resistance, and management will, in three dimensions.

\subsection{The Model of Innovation Resistance (MIR)}

The model of innovation resistance (MIR) was introduced by S. Ram [47]. He stated that innovation resistance is not the obverse of innovation adoption. Instead, for innovation to be adopted, it must overcome some initial resistance. Thus, the length of time of resistance demonstrates whether or not the innovation will be well-received. If resistance is too high, the innovation dies, and adoption will fail. Furthermore, resistance and adoption can coexist during the stages of innovation [47]. Ram identified two main causes of innovation resistance: perceived risk and cognitive resistance [48].

Yoo and Lee [49], who used MIR as the main acceptance theory, shows that with anxiousness and risk-awareness about wrong purchases, consumers feel that they are losing money due to innovation, or that their confidence is threatened. When the information or belief about innovation is unclear and confusing, the consumer becomes psychologically defensive and can resist. Benlian and Hess [50] identified that security threats are the dominant factors influencing IT executives' overall risk perceptions.

Faasen et al. [22] found that customization limitations, lack of vendor trust, loss of control, data security risk, and functionality fit were the main factors causing resistance in cloud-based ERP adoption. Kim [51] proved that three factors are highly correlated with innovation resistance among consumers-relative advantage, complexity, and suitability. The higher the relative advantage, the lower the innovation resistance. The higher the complexity, the higher the innovation resistance and the higher the suitability, but the lower the innovation resistance. It has been verified that innovation resistance has a negative effect on the intention to recommend.

Peng and Gala [21] identified data security and vendor lock-in as barriers to cloud-based ERP adoption. Demi and Haddara [23] posited that barriers in organizations to cloud-based ERP adoption include privacy and security issues, cloud-based ERP system configuration and customization capability level, and vendor lock-in. Abd Elmonem et al. [3] identified the major identified challenges as customization and integration limitations, data ownership, functionality limitations, performance risk, security risk, and service-level agreement (SLA) issues.

\section{Research Model}

The research model illustrated in Figure 1 empirically examines the impact of TOE, innovation, and resistance characteristics on cloud-based ERP adoption intention.

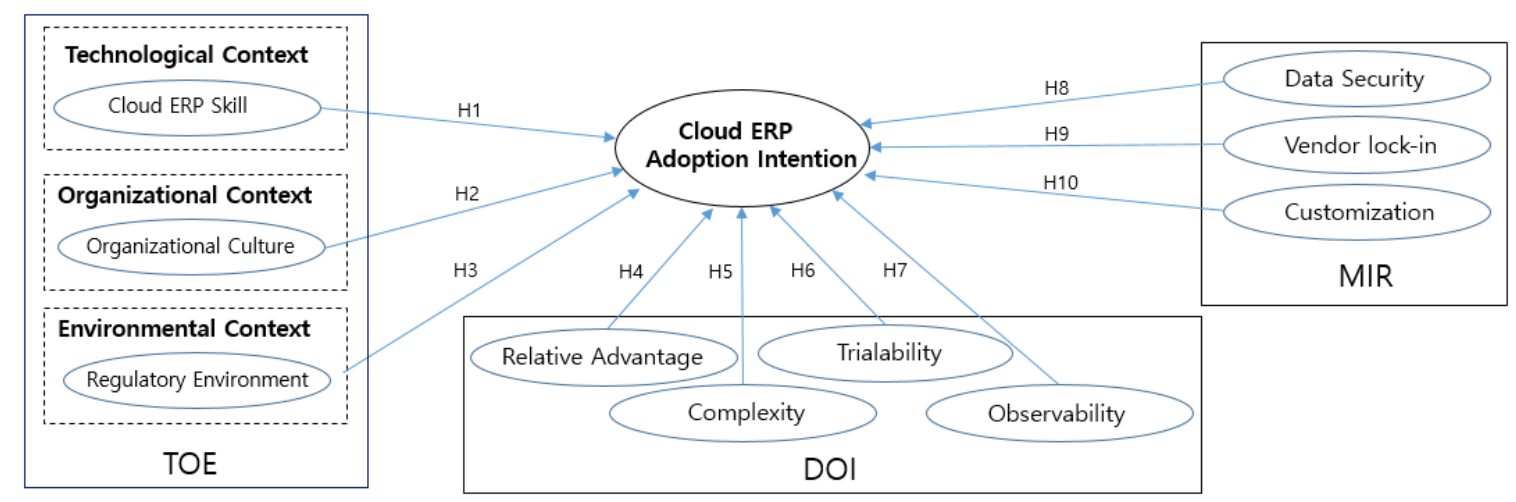

Figure 1. Research model. 


\subsection{Technological Context: Cloud-Based ERP Skill (ICT Skill)}

The technological context includes employees' ICT skills and the ICT infrastructure. Although a cloud-based ERP is undoubtedly a labor-saving and innovative technology, adoption is challenging and confusing due to the fact that it requires essential ICT skills. [52]. Lutovac and Manojlov [53] found that if a company's employees lacked certain ICT skills, they would be upset and eventually lose motivation, investing more time and energy in participating in adopting ERP solutions. SME owners that have poor ICT skills might not be inclined to adopt ICT, and thus perceive IT adoption as difficult [54].

Deficiencies in or a lack of ICT skills and knowledge is a critical challenge affecting most of SMEs [55]. The rapid development of ICT has brought about tremendous business opportunities, as well as challenges. One of these challenges is the need for greater ICT skills and expertise in adopting and implementing emerging technologies [53]. Based on the aforementioned previous studies, it is hypothesized that cloud-based ERP skill positively impacts cloud-based ERP adoption intention.

Hypothesis 1 (H1). Cloud-based ERP skill (IS) is positively (+) related to the intention to adopt cloud-based ERP (IA).

\subsection{Organizational Context: Organizational Culture}

Early research on ERP adoption identified a set of organizational characteristics that might explain why organizations accepted or rejected certain innovations [56]. The most frequently mentioned organizational characteristics influencing cloud-based ERP adoption are organizational culture and high-level management support [57].

Romm et al. [58] showed that the relationship between information systems and organizational culture is critical for companies realizing the potential benefits promised by the system. Organizational culture is both the main driving factor and the impeding factor for cloud-based ERPs in promoting the adoption of innovative technologies [59]. Jone et al. [60] found that organizational culture influences employee attitudes towards ERP adoption, and eventually contributes to the successful implementation of cloud-based ERP. Ke and Wei [61] also noted that cloud-based ERP implementation is related to organizational culture.

When adopting cloud-based ERP, senior management support is considered to be the most important CSF. Senior management in an organization determines the resource allocation required to successfully adopt cloud-based ERP, and approves the project before execution [62,63]. Low et al. [16] revealed that the level of support provided by senior management influenced cloud-based ERP adoption. Based on these findings, we developed the following hypothesis:

Hypothesis 2 (H2). Organizational culture $(O C)$ is positively $(+)$ related to the intention to adopt cloud-based $\operatorname{ERP}(I A)$.

\subsection{Environmental Context: Regulatory Environment}

Environmental context can be divided into the regulatory environment and the competitive environment. The support of the regulatory environment is an important factor in innovation adoption [64-66]. Previous research has discovered that government regulations and policies are critical drivers that might affect the adoption of innovative technologies such as cloud-based ERP, especially in developing countries [67]. $\mathrm{Li}[68]$ believes that an organization is likely to adopt a new technology if the government has a clear obligation to the new technology.

Complying with data, energy, and environmental standards are other difficulties which are faced by cloud-based ERPs, and there are not enough regulations to handle them [3]. Thus, friendly regulatory environments positively contribute to the initiation and adoption of IT [69]. The following hypothesis is based on the above findings: 
Hypothesis 3 (H3). Regulatory environment $(R E)$ is positively $(+)$ related to the intention to adopt cloud-based ERP (IA).

\subsection{Innovation Characteristics}

\subsubsection{Innovation Characteristic: Relative Advantage}

Tornatzky and Kelin [45] described relative advantage as one of the most widely researched innovative features of enterprise IT applications at the firm level. Rogers ([70], p. 229) defined it as "the degree to which an innovation is perceived as being better than the idea it supersedes". Most enterprises adopt cloud-based ERPs, because they understand that doing so will more significantly accelerate communications, save money and time, and lead to the efficient synchronization of new applications of business ideas than traditional ERP systems [16].

Premkumar and Roberts [71] stated that the results of the discriminant analysis of data demonstrated that relative advantage, organizational size, top management support, competitive pressure, and external pressure are they key determinants of information systems adoption. Low et al. [16] discovered that relative advantage, competitive pressure, firm size, top management support, and trading partner pressure characteristics have a significant effect on the adoption of cloud computing. In light of these findings, this study hypothesizes the following:

Hypothesis $4 \mathbf{( H 4 ) . ~ R e l a t i v e ~ a d v a n t a g e ~}(R A)$ is positively $(+)$ related to the intention to adopt cloud-based ERP (IA).

\subsubsection{Innovation Characteristic: Complexity}

Higher complexity is the main reason leading to slower technology adoption [18]. It is defined as "the degree to which an innovation is perceived as relatively difficult to understand and use" ([70], p. 257). Larger organizations feature various complexities such as restrictions in data access; when a high volume of data is handled by a cloud vendor, an organization cannot monitor the software complexity. SMEs have a less complex structure and remain unimpacted by this challenge [72]. Large companies use their ERP, from the standpoint of complexity, to support industry-specific functionality and achieve real-time integration with machinery and other complex legacy systems [38]. The characteristics of SMEs (e.g., smaller size, less complexity) could make the implementation of a cloud-based ERP less complex, thereby encouraging the company to continue with their intention to adopt such a system [73]. Based on the above findings, the following hypothesis is posited:

Hypothesis 5 (H5). Complexity (CO) is negatively (-) related to the intention to adopt cloud-based ERP (IA).

\subsubsection{Innovation Characteristic: Trialability}

Trialability is an important factor that supports the implementation of innovative IT [19,74,75]. Jeyaraj et al. [20] found that trialability has a great influence on the adoption of ICT, such as cloud-based ERP. It is defined as "the degree to which an innovation may be experimented with on a limited basis" ([70], p. 258). Thus, the following hypothesis is put forth:

Hypothesis 6 (H6). Trialability (TR) is positively (+) related to the intention to adopt cloud-based ERP (IA).

\subsubsection{Innovation Characteristic: Observability}

Observability is also an important factor that supports the implementation of innovative IT $[19,74,75]$. Jeyaraj et al. [20] found observability to have a great influence on the adoption of ICT such as cloudbased ERP. It is defined as "the degree to which the results of an innovation are visible to others" ([70], p. 258). Based on these findings, the following hypothesis is put forth: 
Hypothesis 7 (H7). Observability (OB) is positively $(+)$ related to the intention to adopt cloud-based ERP (IA).

\subsection{Resistance Characteristics}

\subsubsection{Resistance Characteristic: Data Security}

It is often said in the industry that cloud vendors are able to provide better IT infrastructure and more effectively protect data security. However, reviewing the literature demonstrates that data leakage and loss is more likely attributable to human causes than technical failures [76].

Specifically, the integrated nature of ERP determines that the data stored in the system can be shared and used by different organizational units. Therefore, managers have access to data in other business areas as well as in their own department. With conventional ERP systems, administrators often save multiple copies of important company data on personal computers (PCs), laptops, hard disk drives and memory sticks. However, if one of these hardware devices is damaged or lost, risk of unauthorized access to the data stored on the devices increases. Moreover, internal employees can download confidential company data from the system and illegally pass it on to competitors for higher profits [76].

If ERP data is hosted by a third-party cloud provider, the client company has less control over who accesses its confidential data. Such a lack of control in the cloud environment inevitably leads to additional threats to customer companies' data security [21]. To ensure confidentiality, a company should establish data security guidelines, and negotiate with its cloud providers [77]. With these investigations, the following hypothesis regarding data security is developed.

Hypothesis 8 (H8). Data security (DS) is negatively (-) related to the intention to adopt cloud-based ERP (IA).

\subsubsection{Resistance Characteristic: Vendor Lock-in}

Overall, the market for cloud-based ERP and cloud services in general is still relatively emerging and immature. Therefore, the quality of cloud-based ERP applications and services provided by different vendors may vary significantly [21]. If a company is not satisfied with their current cloud services, it might inevitably want to switch to another service provider. However, changing to a new cloud-based ERP provider might not be that easy, for several reasons. First, due to the complexity of cloud-based infrastructure, migrating ERP data from one provider to another can be significantly expensive and time-consuming. Second, certain legal restrictions imposed by the current cloud provider might make it difficult for a user company to retrieve and relocate their ERP data to another cloud provider's servers during, or at the end of, an existing service contract. Moreover, the new ERP package is likely to reshape and change business processes, structures, distributions of power, and organizational culture [78].

Therefore, changing an existing ERP package requires making changes in many other organizations, management, and operations. Due to these potential challenges and difficulties, even in the case of unsatisfactory service, a user company might not be able to switch their cloud-based ERP provider. A further review of the literature identified that this issue, often known as the vendor lock-in scenario, occurs very commonly in the cloud environment $[79,80]$. Opara-Martins [81] studied a decision-making framework to mitigate vendor lock-in risks in (SaaS) cloud migration. Vendor lock-in and switching costs have become two significant obstacles to the retirement of cloud-based ERP systems. Using the existing studies, the following hypothesis is developed.

Hypothesis 9 (H9). Vendor lock-in (VL) is negatively (-) related to the intention to adopt cloud-based ERP (IA).

\subsubsection{Resistance Characteristics: Customization}

It is considered that cloud-based ERP is standardized, as everybody uses the same software. It is difficult to customize because the environment is stricter and users have less control, as they do not 
own the system [64]. This is one of the challenges faced by cloud computing in general [82]. System customization is defined as "the degree to which an ERP system was altered to meet the needs of a business unit" ([83], p. 1753).

Johansson et al. [38] was able to develop a framework that shows how SMEs and large enterprises are associated with opportunities and concerns regarding cloud-based ERP adoption. The framework identified the limited customization capabilities of cloud-based ERP and limited integration capabilities, with complex legacy systems as a major concern, especially for large organizations. Abd Elmonem et al. [3] mentioned that customization and integration limitations are some of the key challenges of cloud-based ERP. These limitations do not exist in traditional ERP systems.

Juiz et al. [43] noted that cloud-based ERP systems are less flexible than on-premise systems and offer minimal customization options. So, the lack of configurability and customization negatively affects the adoption of cloud-based ERP systems [13]. Thus, the previous empirical findings lead us to hypothesize the following:

Hypothesis 10 (H10). Customization (CU) is negatively (-) related to the intention to adopt cloud-based ERP (IA).

Table 2 presents the operational definitions of the variables with references.

Table 2. Operational definition of research variables.

\begin{tabular}{ccc}
\hline Variable & Definition & References \\
\hline ICT Skill & $\begin{array}{c}\text { The degree to which the skill level of employees utilizing } \\
\text { IT technologies, such as computer, network, and software }\end{array}$ & {$[52-55]$} \\
\hline Organizational Culture & $\begin{array}{c}\text { The degree to which level of an organization is } \\
\text { responsive and flexible }\end{array}$ & {$[16,56-63]$} \\
\hline Regulatory Environment & $\begin{array}{c}\text { The degree to which less stringent } \\
\text { regulatory environment }\end{array}$ & {$[3,56-63]$} \\
\hline Relative Advantage & $\begin{array}{c}\text { The degree to which an innovation is perceived as being } \\
\text { better than the idea it supersedes }\end{array}$ & {$[45,70,71]$} \\
\hline Complexity & $\begin{array}{c}\text { The degree to which an innovation is perceived as } \\
\text { relatively difficult to understand and use }\end{array}$ & {$[18,38,72,73]$} \\
\hline Trialability & $\begin{array}{c}\text { The degree to which an innovation may be experimented } \\
\text { with on a limited basis }\end{array}$ & {$[19,20,74,75]$} \\
\hline Observability & $\begin{array}{c}\text { The degree to which the results of an innovation are } \\
\text { visible to others }\end{array}$ & {$[19,20,74,75]$} \\
\hline $\begin{array}{c}\text { Dloud-based ERP } \\
\text { Adoption Intention }\end{array}$ & $\begin{array}{c}\text { The degree to which the level of cloud-based ERP } \\
\text { adoption intention }\end{array}$ & {$[21,76,77]$} \\
\hline Vendor Lock-in & $\begin{array}{c}\text { The degree to which legal and contract restrictions on } \\
\text { vendor change }\end{array}$ & {$[21,23,78-81]$} \\
\hline Customization & The degree to which the level of customization limitation & {$[3,13,38,43,64,82,83]$} \\
\hline
\end{tabular}

\section{Research Methodology}

\subsection{Measurements}

A survey was conducted to verify the research model. The measured items regarding TOE and innovation characteristics were selected from prior studies [5-20,24,35,40-46,52-75]. In addition, the measured items regarding resistance characteristics were selected from revisions of existing items to better fit the research context [3,13,21-23,38,47-51,76-83]. Using a five-point Likert scale (1: very strongly disagree to 5 : very strongly agree), all the measurements were scored. In addition, two 
professional information system researchers reviewed the survey to confirm its face validity. Therefore, their inputs were reflected in the final list of items measured as a part of the survey. The detailed items of the survey questionnaire are presented in Appendix A.

\subsection{Data Collection}

Data were collected from chief executive officers (CxOs) (e.g., CEO, CFO, and CIO) or key stakeholders such as IT directors who represented each Korean company adopting and operating ERP systems. The population targeted was $\mathrm{CxOs}$ and key stakeholders of enterprises, because they have the authority make cloud-based ERP system adoption decisions. To generate a list of target companies, we first identified the contact information of those who used an ERP package from an ERP-related company such as SAP, Oracle, Rimini Street, or an IT consulting firm.

Among 500 companies, 159 companies participated in the survey. These companies were SMEs to large enterprises. Survey questionnaires were distributed by phone and e-mail to invite them to participate in the survey. The survey was conducted between February and April 2020. Overall, 159 out of about 500 survey questionnaires were received. Eleven out of the 159 survey questionnaires received were excluded, due to missing answers identified from some part of the responses.

As a result, 148 received survey questionnaires from 148 companies were utilized for the analysis. Most enterprises used SAP or Oracle (62.2\%). The manufacturing portion was $44.6 \%$ and the aboveexecutive portion was $35.8 \%$. If we count above the senior manager level, it was $81.8 \%$. The samples' enterprises and demographics are described in Tables 3 and 4.

Table 3. Descriptive features of respondent enterprises.

\begin{tabular}{|c|c|c|c|}
\hline Respondents $(n=148)$ & & Frequency & Percentage $(\%)$ \\
\hline \multirow{5}{*}{ Annual Revenue Size } & Less than 50M USD & 43 & 29.1 \\
\hline & 50M 300M USD & 26 & 17.6 \\
\hline & 300M 1B USD & 23 & 15.5 \\
\hline & 1B 5B USD & 32 & 21.6 \\
\hline & More than 5B USD & 24 & 16.2 \\
\hline \multirow{6}{*}{ Number of Employees } & Less than 200 & 41 & 27.7 \\
\hline & 200 499 & 28 & 18.9 \\
\hline & 500 999 & 14 & 9.5 \\
\hline & $1000 \sim 4999$ & 37 & 25.0 \\
\hline & 5000 9999 & 10 & 6.8 \\
\hline & More than 10,000 & 18 & 12.1 \\
\hline \multirow{5}{*}{ ERP Package } & SAP & 72 & 48.7 \\
\hline & Oracle & 20 & 13.5 \\
\hline & MS Dynamics & 2 & 1.4 \\
\hline & $\begin{array}{c}\text { Douzone, } \\
\text { Younglimwon(Korean ERP) }\end{array}$ & 36 & 24.3 \\
\hline & Self-Developed & 18 & 12.1 \\
\hline \multirow{6}{*}{ Industry } & Manufacturing & 66 & 44.6 \\
\hline & IT/Communications/Services & 38 & 25.7 \\
\hline & Finance & 14 & 9.5 \\
\hline & Distribution & 14 & 9.5 \\
\hline & Construction & 9 & 6.0 \\
\hline & Others & 7 & 4.7 \\
\hline
\end{tabular}


Table 4. Demographic features of respondents.

\begin{tabular}{cccc}
\hline Respondents $(\mathbf{n}=\mathbf{1 4 8})$ & & Frequency & Percentage (\%) \\
\hline \multirow{2}{*}{ Gender } & Male & 127 & 85.8 \\
& Female & 21 & 14.2 \\
\hline \multirow{2}{*}{ Age } & $30 \mathrm{~s}$ & 29 & 19.6 \\
& $40 \mathrm{~s}$ & 58 & 39.2 \\
& Over 50s & 61 & 41.2 \\
\hline \multirow{2}{*}{ Title } & Manager & 27 & 18.2 \\
& Senior Manager & 68 & 46.0 \\
& Executive & 30 & 20.3 \\
& CIO/CFO/CEO & 23 & 15.5 \\
\hline \multirow{2}{*}{ Department } & IT Planning & 64 & 43.2 \\
& IT Operations & 23 & 15.5 \\
& Finance/Procurement & 37 & 25.1 \\
& Others & 24 & 16.2 \\
\hline
\end{tabular}

\section{Analysis and Results}

Statistical Package for Social Science (SPSS) Version 21 was used to analyze the collected data. The sequence and method of analysis were applied as follows. First, to determine the distribution of enterprises and respondents, frequency and percentages were calculated. Second, validity and reliability tests were conducted. Third, multiple regression analysis was performed to verify the research hypotheses. Lastly, the results and findings are summarized.

\subsection{Measurement Model}

To analyze the validity and reliability of the measurement tools, factor analysis and reliability analysis were performed, respectively. The measurement variables of this study were partially removed through the scale refinement process.

First, exploratory factor analysis (EFA) was conducted to verify validity. All component variables used principal component analysis (PCA) to extract constituent factors, and Varimax was adopted to simplify factor loading. The selection criteria for items in this study were based on an eigenvalue of 1.0 or more and a factor loading of 0.40 or more. Out of 55 question items, two items were removed to fit the theoretical structure and 53 items were used for analysis.

In the reliability analysis, it is considered reliable if the Cronbach's alpha value is 0.6 or higher; all factors are 0.8 or higher in this study. The KMO sample fit is for determining the relevance between variables. Generally, if the KMO value is 0.9 or higher, it is very high, and if it is $0.8 \sim 0.89$, it is rather high. If it is less than 0.5 , it is judged to be unacceptable [84]. The study shows 0.86 , which is moderately acceptable. The Bartlett sphericity test indicates the suitability of the factor analysis model, and is judged as a significant probability. If the significance probability is less than 0.05 , it is possible to facilitate the factor analysis model. In other words, it can be concluded that the use of factor analysis is appropriate, and that common factors exist [85]. The study shows 0.00 , so it can be judged that all of the factor analysis models used in this study are suitable.

Tables 5 and 6 present descriptive statistics of the measurement instruments, and Table 7 shows the results of validity and reliability analyses. 
Table 5. Descriptive statistics of the survey items.

\begin{tabular}{|c|c|c|c|}
\hline Variable & Item & Avg. & S.D. \\
\hline \multirow{5}{*}{ Cloud ERP Skill (ICT Skill) } & IS1 & 3.277 & 1.105 \\
\hline & IS2 & 2.986 & 1.184 \\
\hline & IS3 & 3.122 & 1.298 \\
\hline & IS4 & 2.932 & 1.182 \\
\hline & IS5 & 3.061 & 1.162 \\
\hline \multirow{4}{*}{ Organizational Culture } & OC1 & 3.169 & 1.145 \\
\hline & OC2 & 3.459 & 0.950 \\
\hline & OC4 & 3.378 & 1.103 \\
\hline & OC5 & 3.203 & 1.088 \\
\hline \multirow{5}{*}{ Regulatory Environment } & RE1 & 2.899 & 1.002 \\
\hline & RE2 & 2.655 & 1.022 \\
\hline & RE3 & 3.054 & 1.009 \\
\hline & RE4 & 2.905 & 0.957 \\
\hline & RE5 & 3.054 & 0.909 \\
\hline \multirow{5}{*}{ Relative Advantage } & RA1 & 3.534 & 0.972 \\
\hline & RA2 & 3.358 & 1.024 \\
\hline & RA3 & 3.493 & 0.986 \\
\hline & RA4 & 3.203 & 1.195 \\
\hline & RA5 & 3.480 & 1.020 \\
\hline \multirow{5}{*}{ Complexity } & $\mathrm{CO} 1$ & 2.757 & 0.994 \\
\hline & $\mathrm{CO} 2$ & 3.000 & 1.043 \\
\hline & $\mathrm{CO} 3$ & 3.020 & 1.066 \\
\hline & $\mathrm{CO} 4$ & 2.608 & 0.945 \\
\hline & $\mathrm{CO} 5$ & 3.257 & 1.057 \\
\hline \multirow{5}{*}{ Trialability } & TR1 & 3.541 & 1.033 \\
\hline & TR2 & 3.622 & 1.006 \\
\hline & TR3 & 3.601 & 0.974 \\
\hline & TR4 & 3.547 & 0.950 \\
\hline & TR5 & 3.439 & 1.045 \\
\hline \multirow{4}{*}{ Observability } & OB2 & 3.209 & 0.949 \\
\hline & OB3 & 3.068 & 1.021 \\
\hline & OB4 & 2.912 & 1.112 \\
\hline & OB5 & 2.973 & 1.125 \\
\hline \multirow{5}{*}{ Data Security } & DS1 & 3.439 & 1.191 \\
\hline & DS2 & 3.061 & 1.051 \\
\hline & DS3 & 2.676 & 1.096 \\
\hline & DS4 & 2.973 & 1.240 \\
\hline & DS5 & 3.270 & 1.216 \\
\hline \multirow{5}{*}{ Vendor Lock-In } & VL1 & 3.831 & 0.936 \\
\hline & VL2 & 4.000 & 0.911 \\
\hline & VL3 & 3.669 & 1.033 \\
\hline & VL4 & 3.845 & 0.967 \\
\hline & VL5 & 3.946 & 0.924 \\
\hline \multirow{5}{*}{ Customization } & CU1 & 3.676 & 1.018 \\
\hline & CU2 & 3.527 & 0.965 \\
\hline & CU3 & 3.736 & 0.928 \\
\hline & CU4 & 3.824 & 0.967 \\
\hline & CU5 & 3.669 & 0.986 \\
\hline \multirow{5}{*}{ Cloud ERP Adoption Intention } & IA1 & 2.993 & 1.301 \\
\hline & IA2 & 3.128 & 1.185 \\
\hline & IA3 & 3.162 & 1.184 \\
\hline & IA4 & 2.845 & 1.249 \\
\hline & IA5 & 2.689 & 1.344 \\
\hline
\end{tabular}


Table 6. Correlation of the research variables.

\begin{tabular}{|c|c|c|c|c|c|c|c|c|c|c|c|c|}
\hline & Variable & Avg. & S.D. & 1 & 2 & 3 & 4 & 5 & 6 & 7 & 8 & 9 \\
\hline 1 & Cloud ERP Skill (ICT Skill) & 3.076 & 1.058 & & & & & & & & & \\
\hline 2 & Organizational Culture & 3.302 & 0.963 & $0.652^{* *}$ & & & & & & & & \\
\hline 3 & Regulatory Environment & 2.914 & 0.818 & $0.401^{* *}$ & $0.381^{* *}$ & & & & & & & \\
\hline 4 & Relative Advantage & 3.414 & 0.874 & $0.345^{* *}$ & $0.443 * *$ & $0.460 * *$ & & & & & & \\
\hline 5 & Complexity & 2.928 & 0.846 & -0.205 * & $-0.310 * *$ & 0.073 & $-0.181 *$ & & & & & \\
\hline 6 & Trialability & 3.550 & 0.848 & $0.499^{* *}$ & $0.590 * *$ & $0.434^{* *}$ & $0.467^{* *}$ & $-0.246^{* *}$ & & & & \\
\hline 7 & Observability & 3.041 & 0.926 & $0.482 * *$ & $0.506^{* *}$ & $0.564 * *$ & $0.503 * *$ & -0.060 & $0.571^{* *}$ & & & \\
\hline 8 & Data Security & 3.084 & 0.978 & 0.070 & -0.006 & 0.086 & 0.033 & $0.425^{* *}$ & 0.060 & 0.149 & & \\
\hline 9 & Vendor Lock-In & 3.858 & 0.737 & 0.025 & 0.091 & -0.052 & -0.011 & $0.292 * *$ & 0.136 & 0.041 & $0.351 * *$ & \\
\hline 10 & Customization & 3.686 & 0.846 & 0.035 & 0.022 & 0.087 & -0.057 & $0.390^{* *}$ & 0.040 & -0.008 & $0.279 * *$ & $0.499 * *$ \\
\hline
\end{tabular}

${ }^{*}$ Significant at the 0.05 level (two-tailed), ${ }^{* *}$ Significant at the 0.01 level (two-tailed). 
Table 7. Factor analysis and reliability.

\begin{tabular}{|c|c|c|c|c|c|c|}
\hline Variable & Item & Factor Loading & Communality & Eigenvalue & $\begin{array}{l}\text { Total Variance } \\
\text { Explained }\end{array}$ & $\begin{array}{c}\text { Cronbach's } \\
\alpha\end{array}$ \\
\hline \multirow{5}{*}{$\begin{array}{c}\text { Cloud ERP } \\
\text { Skill (ICT Skill) }\end{array}$} & IS1 & 0.788 & 0.744 & \multirow{5}{*}{4.756} & \multirow{5}{*}{8.973} & \multirow{5}{*}{0.932} \\
\hline & IS2 & 0.871 & 0.855 & & & \\
\hline & IS3 & 0.777 & 0.718 & & & \\
\hline & IS4 & 0.861 & 0.836 & & & \\
\hline & IS5 & 0.804 & 0.831 & & & \\
\hline \multirow{4}{*}{$\begin{array}{l}\text { Organizational } \\
\text { Culture }\end{array}$} & OC1 & 0.581 & 0.786 & \multirow{4}{*}{2.722} & \multirow{4}{*}{5.136} & \multirow{4}{*}{0.915} \\
\hline & OC2 & 0.716 & 0.719 & & & \\
\hline & OC4 & 0.679 & 0.836 & & & \\
\hline & OC5 & 0.728 & 0.851 & & & \\
\hline \multirow{5}{*}{$\begin{array}{l}\text { Regulatory } \\
\text { Environment }\end{array}$} & RE1 & 0.761 & 0.713 & \multirow{5}{*}{3.535} & \multirow{5}{*}{6.670} & \multirow{5}{*}{0.881} \\
\hline & RE2 & 0.723 & 0.764 & & & \\
\hline & RE3 & 0.667 & 0.653 & & & \\
\hline & RE4 & 0.749 & 0.742 & & & \\
\hline & RE5 & 0.796 & 0.713 & & & \\
\hline \multirow{5}{*}{$\begin{array}{c}\text { Relative } \\
\text { Advantage }\end{array}$} & RA1 & 0.789 & 0.801 & \multirow{5}{*}{3.848} & \multirow{5}{*}{7.261} & \multirow{5}{*}{0.894} \\
\hline & RA2 & 0.768 & 0.790 & & & \\
\hline & RA3 & 0.831 & 0.789 & & & \\
\hline & RA4 & 0.710 & 0.726 & & & \\
\hline & RA5 & 0.717 & 0.694 & & & \\
\hline \multirow{5}{*}{ Complexity } & $\mathrm{CO} 1$ & 0.811 & 0.756 & \multirow{5}{*}{3.437} & \multirow{5}{*}{6.485} & \\
\hline & $\mathrm{CO} 2$ & 0.772 & 0.742 & & & \\
\hline & $\mathrm{CO} 3$ & 0.745 & 0.754 & & & 0.878 \\
\hline & $\mathrm{CO} 4$ & 0.793 & 0.719 & & & \\
\hline & $\mathrm{CO} 5$ & 0.649 & 0.638 & & & \\
\hline & TR1 & 0.750 & 0.744 & & & \\
\hline & TR2 & 0.827 & 0.805 & & & \\
\hline Trialability & TR3 & 0.762 & 0.766 & 4.089 & 7.716 & 0.902 \\
\hline & TR4 & 0.716 & 0.671 & & & \\
\hline & TR5 & 0.692 & 0.713 & & & \\
\hline & OB2 & 0.593 & 0.652 & & & \\
\hline & OB3 & 0.734 & 0.817 & & & \\
\hline Observability & OB4 & 0.781 & 0.804 & 2.989 & 5.640 & 0.897 \\
\hline & OB5 & 0.779 & 0.797 & & & \\
\hline & DS1 & 0.782 & 0.726 & & & \\
\hline & DS2 & 0.849 & 0.795 & & & \\
\hline Data Security & DS3 & 0.755 & 0.755 & 3.822 & 7.212 & 0.902 \\
\hline & DS4 & 0.850 & 0.814 & & & \\
\hline & DS5 & 0.807 & 0.795 & & & \\
\hline & VL1 & 0.659 & 0.585 & & & \\
\hline & VL2 & 0.801 & 0.737 & & & \\
\hline Vendor Lock-In & VL3 & 0.621 & 0.677 & 3.134 & 5.913 & 0.835 \\
\hline & VL4 & 0.771 & 0.726 & & & \\
\hline & VL5 & 0.715 & 0.708 & & & \\
\hline & CU1 & 0.842 & 0.786 & & & \\
\hline & CU2 & 0.854 & 0.804 & & & \\
\hline Customization & CU3 & 0.764 & 0.715 & 3.961 & 7.473 & 0.917 \\
\hline & CU4 & 0.796 & 0.734 & & & \\
\hline & CU5 & 0.881 & 0.843 & & & \\
\hline & IA1 & 0.791 & 0.867 & & & \\
\hline Cloud ERP & IA2 & 0.703 & 0.827 & & & \\
\hline Adoption & IA3 & 0.736 & 0.861 & 4.082 & 7.703 & 0.952 \\
\hline Intention & IA4 & 0.777 & 0.833 & & & \\
\hline & IA5 & 0.836 & 0.862 & & & \\
\hline
\end{tabular}




\subsection{Hypothesis Test}

Multiple regression analysis was performed to verify the hypothesis. The multiple regression analysis is used to verify the causal relationship between two or more independent variables and one dependent variable. Since there are two or more independent variables, multicollinearity may occur. Multicollinearity means the possibility of a high correlation between independent variables. The basic assumption of the regression model is that there is no correlation between the independent variables. However, the occurrence of multicollinearity results in ignoring the basic assumption of the regression model. To diagnose multicollinearity, we examined tolerance and variance inflation factor (VIF). As shown in Table 8, the VIFs of the independent variables are generally low (all of them are much less than 10). All of the tolerance values of the independent variables are also greater than 0.1. So, multicollinearity is not present in our model [84].

Table 8. Regression test results.

\begin{tabular}{|c|c|c|c|c|c|c|c|}
\hline \multirow{2}{*}{ Variable } & \multicolumn{2}{|c|}{$\begin{array}{l}\text { Unstandardized } \\
\text { Coefficients }{ }^{1}\end{array}$} & \multirow{2}{*}{$\begin{array}{c}\begin{array}{c}\text { Standardized } \\
\text { Coefficients }\end{array} \\
\text { Beta }\end{array}$} & \multirow{2}{*}{ t-Value } & \multirow{2}{*}{ Sig. } & \multicolumn{2}{|c|}{$\begin{array}{l}\text { Collinearity } \\
\text { Statistics }\end{array}$} \\
\hline & B & Std. Error & & & & Tolerance & VIF \\
\hline (Constant) & -0.624 & 0.433 & & -1.439 & 0.152 & & \\
\hline ICT Skill (IS) & 0.048 & 0.072 & 0.044 & 0.672 & 0.503 & 0.521 & 1.920 \\
\hline Organizational Culture (OC) & 0.385 & 0.087 & 0.322 & 4.451 & 0.000 & 0.432 & 2.316 \\
\hline Regulatory Environment (RE) & 0.205 & 0.090 & 0.145 & 2.283 & 0.024 & 0.556 & 1.798 \\
\hline Relative Advantage (RA) & 0.318 & 0.079 & 0.241 & 4.048 & 0.000 & 0.636 & 1.573 \\
\hline Complexity $(\mathrm{CO})$ & 0.038 & 0.086 & 0.028 & 0.447 & 0.656 & 0.568 & 1.760 \\
\hline Trialability (TR) & 0.405 & 0.092 & 0.298 & 4.410 & 0.000 & 0.493 & 2.026 \\
\hline Observability (OB) & 0.027 & 0.085 & 0.022 & 0.322 & 0.748 & 0.484 & 2.066 \\
\hline Data Security (DS) & -0.050 & 0.066 & -0.042 & -0.754 & 0.452 & 0.727 & 1.376 \\
\hline Vendor lock-in (VL) & -0.254 & 0.093 & -0.162 & -2.736 & 0.007 & 0.641 & 1.561 \\
\hline Customization (CU) & -0.005 & 0.079 & -0.003 & -0.057 & 0.955 & 0.662 & 1.510 \\
\hline
\end{tabular}

The correlation between the independent variable and the dependent variable showed a high correlation of 0.831 . The R-squared value was found to be 0.691 , which means that independent variables account for $69.1 \%$ of the dependent variable, cloud-based ERP adoption intention, IA. The adjusted $\mathrm{R}$-squared value was 0.669. Durbin-Watson has a value of 2.041, which is close to 2; since it is not close to 0 or 4 , there is no correlation between the residuals, so it can be interpreted that the regression model is suitable. Since the F-value was 30.676 and the probability of significance was $0.000(p<0.05)$, the regression line was found to fit the model.

As a result of examining the relationship between cloud-based ERP skill (IS), which is the technological context variable, and cloud-based ERP adoption intention (IA), Hypothesis 1 was rejected, with a t-value of 0.672 and a $p$-value of 0.503 . On the other hand, as a result of grasping the impact relationship between organizational culture (OC), which is the organizational context, and IA, the t-value was 4.451 and the $p$-value was 0.000, so Hypothesis 2 was adopted with statistical significance. In addition, as a result of understanding the impact relations between the regulatory environment (RE), which is the environmental context, and IA, the t-value was 2.283 and the $p$-value was 0.024 , so Hypothesis 3 was adopted with $p<0.05$ statistical significance. Among the innovation characteristics, relative advantage (RA) and trialability (TR) are related to IA, respectively, where the t-value is 4.048 , the $p$-value is 0.000 , the $t$-value is 4.410 , the $p$-value is 0.000 , and Hypotheses 4 and 6 are $p<0.05$. These were adopted by securing statistical significance. However, complexity $(\mathrm{CO})$ and observability $(\mathrm{OB})$ were rejected with $\mathrm{t}$-values of 0.447 and 0.322 , respectively, in relation to IA. Among resistance characteristics, vendor lock-in (VL) is related to IA, $\mathrm{t}$-value is $-2.736, p$-value is 0.007 , and statistical significance is secured. Hypothesis 9 was adopted. Data security (DS) and customization (CU), Hypotheses 8 and 10, were rejected because they were not statistically significant $(p>0.05)$ while their $\mathrm{t}$-values were -0.754 and -0.057 , respectively. Summarizing the above hypotheses verification analysis, the figure (Figure 2) and table (Table 9) are as follows. 


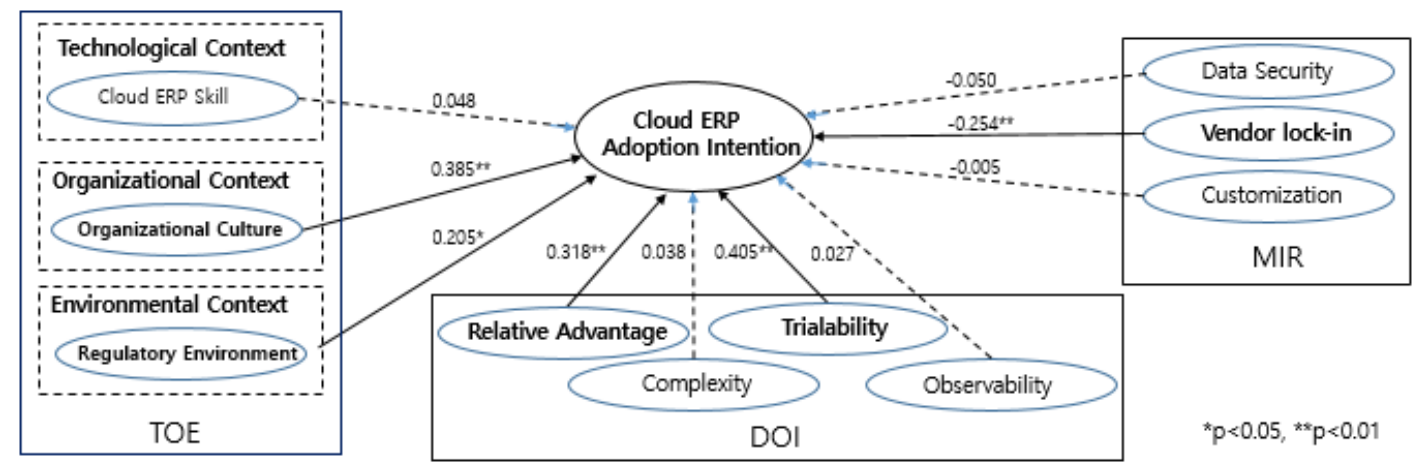

Figure 2. Results of the regression model.

Table 9. Hypothesis testing.

\begin{tabular}{ccccc}
\hline Hypothesis & Path & t-Value & Sig. & Assessment $(p<0.05)$ \\
\hline H1 & IS $\rightarrow$ IA & 0.672 & 0.503 & Not Supported \\
\hline H2 & OC $\rightarrow$ IA & 4.451 & 0.000 & Supported \\
\hline H3 & RE $\rightarrow$ IA & 2.283 & 0.024 & Supported \\
\hline H4 & RA $\rightarrow$ IA & 4.048 & 0.000 & Supported \\
\hline H5 & CO $\rightarrow$ IA & 0.447 & 0.656 & Not Supported \\
\hline H6 & TR $\rightarrow$ IA & 4.410 & 0.000 & Supported \\
\hline H7 & OB $\rightarrow$ IA & 0.322 & 0.748 & Not Supported \\
\hline H8 & DS $\rightarrow$ IA & -0.754 & 0.452 & Not Supported \\
\hline H9 & VL $\rightarrow$ IA & -2.736 & 0.007 & Supported \\
\hline H10 & CU $\rightarrow$ IA & -0.057 & 0.955 & Not Supported \\
\hline
\end{tabular}

\section{Discussion and Conclusions}

\subsection{Discussion of Findings}

The study focuses on the intention to adopt cloud-based ERP using the TOE framework, innovation characteristics, and resistance characteristics. There have been prior studies in which TOE or DOI was used in the analysis of factors affecting cloud-based ERP adoption, but there were very few cases of comprehensive analysis using the TOE and DOI frameworks, and as far as we know, this is the first comprehensive empirical study that integrates the TOE, DOI, and MRI frameworks. This study comprehensively examined the significant relationship between technology, organizational and environmental context; innovation characteristics; resistance characteristics; and the intention to adopt cloud-based ERP. This study has identified the factors affecting the intention to successfully adopt cloud-based ERP.

The empirical analysis results showed that organization culture, regulatory environment, relative advantage, trialability, and vendor lock-in each had a significant influence $(p<0.05)$ on the intention to adopt cloud-based ERP, while ICT skill, complexity, observability, data security and customization had no significant influence $(p>0.05)$ on the intention to adopt cloud-based ERP.

Although ICT skill and complexity were considered to be important variables on the intention to adopt cloud-based ERP, the result of the empirical analysis was not statistically significant in this study. As for resistance characteristics, only vendor lock-in is statistically valid, and data security and customization limitations, which are generally in question, are insignificant. It seems that cloud-based ERP providers have achieved more results than in the past and trust from future prospects.

According to this study, organizational culture was identified to be important. To adopt cloud-based $E R P$, it is necessary to revitalize the organizational culture. Organizations should be responsive and flexible in adopting cloud-based ERP. In addition, it should be an organizational culture that is shared, 
open, and easy to accept, regarding the direction of company operations. It would be desirable if the learning organization or community of practice $(\mathrm{CoP})$ was prepared to create a free forum for discussion regarding cloud-based ERP adoption.

Second, since the regulatory environment is identified as an important factor in the adoption of cloud-based ERP, it is important to relax laws and regulations for the activation of cloud-based ERP by government agencies. This study reveals that the role of the government is important. The role of the company is also important, but the government will need to loosen regulations. In the case of Korea, the so-called "Three Data Acts" have recently been passed to remove the obstacles to cloud-based ERP adoption. If this regulation creates an increasingly favorable environment, this study suggests that cloud-based ERP adoption can be expanded even further. The easing of these government regulations and policies will enhance national competitiveness as well as corporate competitiveness, through the fourth industrial development, including cloud-based ERP.

Third, relative advantage proved to be a very important factor, and the efficiency and effectiveness of an organization will be improved through the adoption of cloud-based ERP. It is also expected and confirmed to be provided with timely information for decision-making. In addition to the simple cost reduction effect, this study suggests that the messages that cloud-based ERP vendors emphasize are receiving the relative advantage of being able to respond quickly and flexibly, as businesses expand and pay as much as they use.

Fourth, since cloud-based ERP is a relatively new concept, it is important to try and experience it. Before the actual adoption of cloud-based ERP, it is necessary to demonstrate how it fits in with an organization and make sure that the requirements can be reflected to minimize trial and error before actual use. It is important for cloud-based ERP suppliers to be open to the possibility of trial before adopting cloud-based ERP. It should be possible to meet needs, by developing a formal demo scenario that is simple but sufficiently experienced and capable of helping adoption decisions. This study suggests that implementing a trial and buy program, or a limited experience to get you started to make sure that the project is right for your organization, before the adoption decision can contribute to maximum performance under the appropriate investment, that is, the expansion of the cloud-based ERP market.

Fifth, regarding vendor lock-in, which was verified as a resistance factor for cloud-based ERP adoption, it was verified that this was the most worrying factor among the various resistance factors. It is recognized that the quality of service is different depending on the cloud-based ERP vendor, and it is vendor-dependent, because it can be contracted, technically, or on the vendor product roadmap, because it is very difficult to move to another solution vendor after using a specific cloud-based ERP vendor solution. It is understood in this study that there is a reluctance to adopt cloud-based ERP.

\subsection{Theoretical Implications}

The study has three academic implications. First, factors influencing the adoption of cloud-based ERP were identified from the comprehensive perspective. To answer what leads to cloud-based ERP adoption, an integrated research model was presented and analyzed through empirical analysis. Specifically, the TOE framework was introduced for analyzing factors from the comprehensive viewpoint. Applying the TOE framework to cloud-based ERP adoption was not only done in our research, but also in Saudi Arabia and in Taiwan. This study comprehensively analyzed the effects by bringing the TOE framework, ICT skills from the T perspective, organizational culture from the $\mathrm{O}$ perspective, and regulatory environment variables from the E perspective.

Second, it is said that the TOE framework was introduced earlier. The TOE framework has the limitation that it cannot consider the characteristics of an innovative technology such as cloud-based ERP. Therefore, because cloud-based ERP is an innovative technology that is very different from traditional $E R P$, it is a research subject that has characteristics that make it very important to reflect such innovation characteristics in the model. Therefore, to reflect this in the model, the main factors of innovation characteristics were used as variables, in accordance with DOI theory. However, in recent studies, many studies have reported that resistance in an organization becomes difficult when new innovative 
technologies are introduced. According to studies that researched the user's perception of cloud-based ERP, there are many positive views of cloud-based ERP, but there are also many negative views of cloud-based ERP as well. In a paper recently published in Taiwan [35], both motivational factors and risk factors were considered simultaneously. Accepting that view, we also considered factors, not only in terms of innovation characteristics but also in terms of innovation resistance. In particular, data security concerns, vendor lock-in concerns, and customization concerns were discovered as variables for specialized innovation resistance factors affecting cloud-based ERP adoption. Based on these discovered variables, this is the second theoretical implication of this study.

Third, this study targeted and investigated companies of a wide variety of industries and sizes. In addition, in the research of these companies, it was very important to know who from the company received the questionnaire from. This determines the quality of the analysis, which was emphasized previously, but it is also a theoretical implication that the participation of individuals from the $\mathrm{CxO}$ level in our study is very high.

\subsection{Practical Implications}

The study has three practical implications. First, the study provides implications for companies seeking to introduce cloud-based ERP under the COVID-19 environment. Companies may have increased interest in cloud-based ERP because of COVID-19, because it increases the sustainability of business operations. However, even if it is a meaningful tool or infrastructure, it is difficult for IT to succeed if the acceptance level of the entire organization is low. However, it is necessary to find and supplement factors to promote or inhibit this, and this study provides a way to do this. Specifically, according to this study, organizational culture and relative advantage are important. In particular, it is emphasized that organizational culture is important, so it is necessary to have a good cultural background.

Second, it suggests that the role of the company is important, but the role of the government is also important to the expansion of cloud-based ERP adoption. We considered the variable for regulation as an environmental variable, but it turned out that there are many companies that take the regulations seriously. This study suggests that the role of government is significant in expanding cloud-based ERP. In particular, when introducing cloud-based ERP, there may be cases where it is not possible to introduce cloud-based ERP, including information that is the ankle caught, such as information protection, personal information protection, or security. In particular, there are many organizations that are reluctant to use the public cloud, and if such institutional supplementation is not made in these places, it may become difficult to activate.

Third, it offers strategic direction to ERP vendors. As a result of this study, since relative advantage and trialability were important, this may be a good way to emphasize the relative advantages in this case study, for example, and induce them to try using them when formulating sales strategies. However, the point to be aware of is that ERP companies are very worried that customer companies are locked into certain vendors. So, for example, when persuading a client, it suggests that it is a necessary sales strategy to instill the perception that we are not targeting to control you, but that we are partners that share success with each other.

Based on the results, it seems necessary to target companies with flexible organizational cultures. Another suggestion that can be derived from the study could be cooperating more with the government and related organizations, so that regulatory factors such as government regulations can be promptly resolved. Moreover, it is necessary to emphasize the relative advantage, which could make it possible to experience cloud-based ERP on a trial basis and develop successful cloud-based ERP customer cases for marketing, so that customers can easily observe them. These findings will give practical insights and guidelines to key decision-makers for cloud-based ERP adoption.

\subsection{Limitations and Future Research Directions}

There are three research limitations and future research directions of this study. First, it was good to introduce the TOE viewpoint, but because there are too many variables in the model, only one factor 
per $\mathrm{T}, \mathrm{O}$, and $\mathrm{E}$, respectively, was considered. However, according to other papers that introduced the TOE framework [5-15,35,42], in addition to ICT skill, ICT infrastructure, information quality, etc., were also considered as the technology context. In addition to organizational culture, we considered, top management support and enterprise size are considerable. Furthermore, in the environmental context, in addition to the regulatory environment, we can also consider competitive environment, industry pressure, etc. In future studies, these factors should be considered more comprehensively.

Second, since the results of this study were analyzed by questionnaires collected in Korea, the results might be limited to Korea. In fact, there are some mismatched results with previous studies conducted overseas. For example, although previous research in Saudi Arabia has shown that ICT skill and complexity were strongly related to cloud-based ERP adoption, while organizational culture and trialability had no significant influence [6], this study demonstrates that organizational culture and trialability have a significant influence on cloud-based ERP adoption, while ICT skill and complexity have no significant impact. The results from AlBar and Hoque's [6] study were directly opposite of those from Korean companies. According to a previous study in South Africa, customization negatively influenced the decision to adopt [60]. From another study in the UK, data security and limited customization were identified as major concerns, particularly relevant to large organizations [38]. Because each country's environment is different, the findings show that these factors' impacts on adoptability can vary from country to country. Therefore, it is necessary to check whether the country context has a moderating effect on the effects of factors, through comparative studies between countries in the future.

Third, COVID-19 events continue to have a significant negative impact on business operations globally. Thus, it is also necessary to examine how the COVID-19 pandemic affects the intention to adopt cloud-based ERP. The greater the impact of COVID-19, the greater demand for non-contact operations, which may increase the demand for cloud-based ERP in countries suffering from COVID-19. Thus, we have a future plan to expand our study, to see if COVID-19 patient ratios or the degree of containment caused by COVIDs will impact adoption of cloud-based ERP.

In addition, as a new research topic, vendor lock-in is disliked and cloud-based ERP is expensive at the beginning, so companies are starting to choose a completely new third-party alternative. The alternative is to choose companies called third-party maintenance (3PM). If you choose 3PM, you can continue to use the existing on-premises ERP. This is a third alternative to avoid vendor lock-in. Recently, sales of 3PM companies such as Rimini Street have greatly expanded. In this study, we analyzed whether to adopt cloud-based ERP, but in the future, among the two alternatives, the adoption of cloud-based ERP and the transition to 3PM, what will companies decide? It seems to be necessary to conduct such a comparative study in the future.

Author Contributions: Conceptualization, B.A. and H.A.; methodology, B.A. and H.A.; software, B.A. and H.A.; validation, B.A. and H.A.; formal analysis, B.A. and H.A.; investigation, B.A.; resources, B.A.; data curation, B.A.; writing — original draft preparation, B.A.; writing—review and editing, B.A. and H.A.; visualization, B.A.; supervision, H.A.; project administration, B.A.; funding acquisition, B.A. and H.A. All authors have read and agreed to the published version of the manuscript.

Funding: This research received no external funding.

Conflicts of Interest: The authors declare no conflict of interest. The funders had no role in the design of the study; in the collection, analyses, or interpretation of data; in the writing of the manuscript, or in the decision to publish the results.

\section{Abbreviations}

$\begin{array}{ll}\text { ERP } & \text { Enterprise resource planning } \\ \text { TOE } & \text { Technology-organization-environment } \\ \text { DOI } & \text { Diffusion of innovation } \\ \text { MIR } & \text { Model of innovation resistance } \\ \text { ICT } & \text { Information and communications technology }\end{array}$




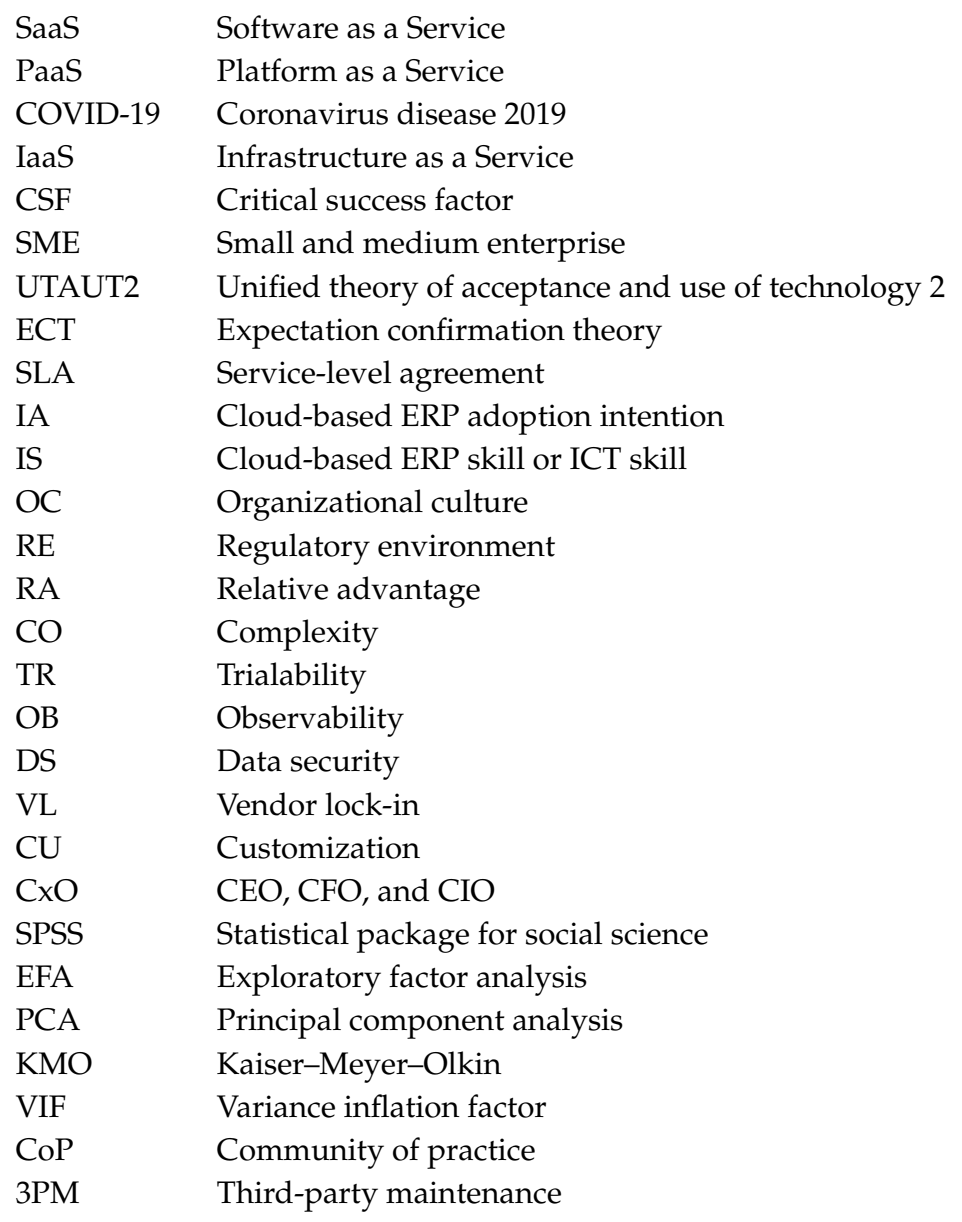

\section{Appendix A}

Table A1. Measurement Items.

\begin{tabular}{|c|c|c|c|}
\hline Variable & Item & Measurement (Five-Point Likert Scale) & References \\
\hline \multirow{5}{*}{$\begin{array}{l}\text { Cloud ERP Skill } \\
\quad \text { (ICT Skill) }\end{array}$} & IS1 & $\begin{array}{l}\text { Employees in our company are generally aware of the functions } \\
\text { of cloud-based ERP. }\end{array}$ & \multirow{5}{*}{ [52-55] } \\
\hline & IS2 & Employees in our company are well trained in cloud-based ERP. & \\
\hline & IS3 & $\begin{array}{c}\text { Our company is supported by specialized or knowledgeable } \\
\text { personal for cloud-based ERP. }\end{array}$ & \\
\hline & IS4 & $\begin{array}{l}\text { Employees in our company have enough opportunity to train } \\
\text { new technologies including cloud-based ERP. }\end{array}$ & \\
\hline & IS5 & $\begin{array}{l}\text { Employees in our company have a high level of understanding } \\
\text { of new technologies including cloud-based ERP. }\end{array}$ & \\
\hline \multirow{4}{*}{$\begin{array}{l}\text { Organizational } \\
\text { Culture }\end{array}$} & OC1 & $\begin{array}{c}\text { Our company is responsive and flexible in adopting } \\
\text { cloud-based ERP. }\end{array}$ & \multirow{4}{*}[16,56-63]{} \\
\hline & OC2 & $\begin{array}{l}\text { There is a high level of agreement about how we operate in } \\
\text { this company. }\end{array}$ & \\
\hline & OC4 & $\begin{array}{l}\text { Our company has an open and receptive organizational culture } \\
\text { in adopting cloud-based ERP. }\end{array}$ & \\
\hline & OC5 & $\begin{array}{l}\text { Our company has an organizational culture suitable for } \\
\text { cloud-based ERP adoption. }\end{array}$ & \\
\hline
\end{tabular}


Table A1. Cont.

\begin{tabular}{|c|c|c|c|}
\hline Variable & Item & Measurement (Five-Point Likert Scale) & References \\
\hline \multirow{5}{*}{$\begin{array}{l}\text { Regulatory } \\
\text { Environment }\end{array}$} & RE1 & $\begin{array}{l}\text { The laws and regulations of the government support } \\
\text { cloud-based ERP initiatives and implementation. }\end{array}$ & \multirow{5}{*}[3,64-69]{} \\
\hline & RE2 & $\begin{array}{l}\text { The government drives the use of cloud ERP through } \\
\text { incentive programs. }\end{array}$ & \\
\hline & RE3 & $\begin{array}{l}\text { The company requires maintaining the regulatory environment } \\
\text { in the use of cloud-based ERP. }\end{array}$ & \\
\hline & RE4 & $\begin{array}{l}\text { The government policy has a positive impact on cloud-based } \\
\text { ERP adoption. }\end{array}$ & \\
\hline & RE5 & $\begin{array}{c}\text { Various government regulations that are hindering cloud-based } \\
\text { ERP adoption are being relaxed. }\end{array}$ & \\
\hline \multirow{5}{*}{$\begin{array}{l}\text { Relative } \\
\text { Advantage }\end{array}$} & RA1 & Cloud-based ERP will enhance the efficiency of our company. & \multirow{5}{*}[45,70,71]{} \\
\hline & RA2 & $\begin{array}{l}\text { Cloud-based ERP will improve the performance of } \\
\text { our company. }\end{array}$ & \\
\hline & RA3 & $\begin{array}{l}\text { Cloud-based ERP will provide timely information } \\
\text { for decision making. }\end{array}$ & \\
\hline & RA4 & $\begin{array}{c}\text { With cloud-based ERP adoption, we expect to see cost } \\
\text { savings effect. }\end{array}$ & \\
\hline & RA5 & $\begin{array}{l}\text { With cloud-based ERP adoption, we will be able to respond } \\
\text { quickly and flexibly to our business expansion and pay only for } \\
\text { what we use. }\end{array}$ & \\
\hline \multirow{5}{*}{ Complexity } & $\mathrm{CO} 1$ & We believe that cloud-based ERP is difficult to use. & \multirow{5}{*}[18,38,72,73]{} \\
\hline & $\mathrm{CO} 2$ & $\begin{array}{l}\text { Integrating cloud-based ERP in our work practices will } \\
\text { be difficult. }\end{array}$ & \\
\hline & $\mathrm{CO} 3$ & $\begin{array}{c}\text { Our company may encounter some difficulties in maintaining } \\
\text { the cloud-based ERP platform. }\end{array}$ & \\
\hline & $\mathrm{CO} 4$ & Cloud-based ERP is complex to use. & \\
\hline & $\mathrm{CO} 5$ & $\begin{array}{l}\text { Our company is expected to have a long stabilization period for } \\
\text { stable use after cloud-based ERP adoption. }\end{array}$ & \\
\hline \multirow{5}{*}{ Trialability } & TR1 & $\begin{array}{c}\text { The company experiments on cloud service applications before } \\
\text { deciding whether to use it. }\end{array}$ & \multirow{5}{*}[19,20,74,75]{} \\
\hline & TR2 & $\begin{array}{l}\text { We were allowed to use cloud-based ERP services on an } \\
\text { experimental basis long enough to understand how it fits into } \\
\text { the company. }\end{array}$ & \\
\hline & TR3 & It is easy to correct mistakes when using cloud-based ERP. & \\
\hline & TR4 & $\begin{array}{l}\text { Before cloud-based ERP adoption, it is possible to confirm } \\
\text { whether the requirements of the company can be reflected. }\end{array}$ & \\
\hline & TR5 & $\begin{array}{c}\text { Before cloud-based ERP adoption, the company's additional } \\
\text { requirements can be reflected. }\end{array}$ & \\
\hline \multirow{4}{*}{ Observability } & OB2 & $\begin{array}{l}\text { It is easy to observe the benefits of partner cloud-based } \\
\text { ERP usage. }\end{array}$ & \multirow{4}{*}[19,20,74,75]{} \\
\hline & OB3 & We have seen many partners use cloud-based ERP. & \\
\hline & OB4 & $\begin{array}{c}\text { It is observed that companies in the same industry are using } \\
\text { cloud-based ERP. }\end{array}$ & \\
\hline & OB5 & $\begin{array}{c}\text { It is observed that companies of the same size use } \\
\text { cloud-based ERP. }\end{array}$ & \\
\hline
\end{tabular}


Table A1. Cont.

\begin{tabular}{|c|c|c|c|}
\hline Variable & Item & Measurement (Five-Point Likert Scale) & References \\
\hline \multirow{5}{*}{ Data Security } & DS1 & $\begin{array}{l}\text { There are poor data protection practices adopted by companies } \\
\text { and cloud vendors. }\end{array}$ & \multirow{5}{*}[21,76,77]{} \\
\hline & DS2 & $\begin{array}{l}\text { We have seen unauthorized data access occurred in } \\
\text { client companies. }\end{array}$ & \\
\hline & DS3 & $\begin{array}{l}\text { We have seen unauthorized data access occurred in } \\
\text { cloud providers. }\end{array}$ & \\
\hline & DS4 & $\begin{array}{l}\text { Cloud-based ERP's data security is a concern because it is } \\
\text { unclear where the data storage is located. }\end{array}$ & \\
\hline & DS5 & $\begin{array}{l}\text { We are concerned about the privacy of sensitive data held by } \\
\text { our company due to inconsistent data protection laws. }\end{array}$ & \\
\hline \multirow{5}{*}{ Vendor Lock-In } & VL1 & $\begin{array}{l}\text { We can experience variance in the service quality of different } \\
\text { cloud vendors. }\end{array}$ & \multirow{5}{*}[21,23,78-81]{} \\
\hline & VL2 & $\begin{array}{c}\text { We can face the high cost of ERP re-migration after using } \\
\text { cloud-based ERP. }\end{array}$ & \\
\hline & VL3 & $\begin{array}{l}\text { It would be very difficult to change a cloud vendor due to legal } \\
\text { and contractual restrictions. }\end{array}$ & \\
\hline & VL4 & $\begin{array}{l}\text { When adopting a cloud-based ERP of a specific vendor, it is } \\
\text { unavoidable to accept the guidelines of the vendor even if it } \\
\text { is unreasonable. }\end{array}$ & \\
\hline & VL5 & $\begin{array}{l}\text { After adopting a cloud-based ERP of a specific vendor, there is } \\
\text { no choice but to follow the product roadmap of the vendor. }\end{array}$ & \\
\hline \multirow{5}{*}{ Customization } & CU1 & We have customization limitations on cloud-based ERP. & \multirow{5}{*}[3,13,38,43,64,82-84]{} \\
\hline & CU2 & The customization ability of cloud-based ERP is very limited. & \\
\hline & CU3 & $\begin{array}{l}\text { We believe it is not easy to migrate to cloud-based ERP due to } \\
\text { heavy customization. }\end{array}$ & \\
\hline & CU4 & Developing custom code in cloud-based ERP is expensive. & \\
\hline & CU5 & $\begin{array}{l}\text { It is not easy to develop with custom code after cloud-based } \\
\text { ERP adoption. }\end{array}$ & \\
\hline \multirow{5}{*}{$\begin{array}{l}\text { Cloud-based } \\
\text { ERP Adoption } \\
\text { Intention }\end{array}$} & IA1 & We strongly intend to use cloud-based ERP in our company. & \multirow{5}{*}[5-7,21,32-35]{} \\
\hline & IA2 & We like the idea of using cloud-based ERP systems. & \\
\hline & IA3 & $\begin{array}{l}\text { Overall, we have a favorable attitude toward cloud-based } \\
\text { ERP implementation. }\end{array}$ & \\
\hline & IA4 & $\begin{array}{c}\text { Our company is deeply discussing the adoption of } \\
\text { cloud-based ERP. }\end{array}$ & \\
\hline & IA5 & Our company is preparing for the adoption of cloud-based ERP. & \\
\hline
\end{tabular}

\section{References}

1. Magic Quadrant for Cloud Core Financial Management Suites for Midsize, Large and Global Enterprises. Available online: https:/www.gartner.com/en/documents/3913508/magic-quadrant-for-cloud-core-financialmanagement-suite (accessed on 18 June 2020).

2. Bjelland, E.; Haddara, M. Evolution of ERP systems in the cloud: A study on system updates. Systems 2018, 6, 22. [CrossRef]

3. Elmonem, M.A.A.; Nasr, E.S.; Geith, M.H.; Ali, M. Benefits and challenges of cloud ERP systems-A systematic literature review. Futur. Comput. Inform. J. 2016, 1, 1-9. [CrossRef]

4. Van der Borg, F.F.; Eshuis, H.; Kusters, R.J. Customization in Cloud-Based Enterprise Resource Planning Systems. Master's Thesis, Eindhoven University of Technology, Eindhoven, The Netherlands, 2017.

5. Kinuthia, J.N. Technological, Organizational, and Environmental Factors Affecting the Adoption of Cloud Enterprise Resource Planning (ERP) Systems. Ph.D. Thesis, Eastern Michigan University, Ypsilanti, MI, USA, 2014. 
6. Albar, A.M.; Hoque, R. Factors affecting cloud ERP adoption in Saudi Arabia: An empirical study. Inf. Dev. 2017, 35, 150-164. [CrossRef]

7. Al-Shboul, M.A. Towards better understanding of determinants logistical factors in SMEs for cloud ERP adoption in developing economies. Bus. Process. Manag. J. 2019, 25, 887-907. [CrossRef]

8. Gangwar, H.; Date, H.; Ramaswamy, R. Understanding determinants of cloud computing adoption using an integrated TAM-TOE model. J. Enterp. Inf. Manag. 2015, 28, 107-130. [CrossRef]

9. Albar, A.M.; Hoque, R. Determinants of Cloud ERP Adoption in Saudi Arabia: An Empirical Study. In Proceedings of the 2015 International Conference on Cloud Computing (ICCC), Riyadh, Saudi Arabia, 26-29 April 2015; Institute of Electrical and Electronics Engineers (IEEE): Piscataway, NJ, USA, 2015; pp. 1-4.

10. Lee, Y.-H.; Hsu, P.; Chang, Y.-W.; Cheng, Y.-S. Integrating TRA and toe Frameworks for Cloud ERP Switching Intention by Taiwanese Company. In Proceedings of the PACIS, Chiayi, Taiwan, 27 June-1 July 2016; PACIS: Budapest, Hungary, 2016; pp. 139-148.

11. Usman, U.M.Z.; Ahmad, M.N.; Zakaria, N.H. The determinants of adoption of cloud-based erp of Nigerian's SMES manufacturing sector using toe framework and doi theory. Int. J. Enterp. Inf. Syst. 2019, 15, 27-43. [CrossRef]

12. Qian, L.Y.; Baharudin, A.S.; Kanaan-Jebna, A. Factors affecting the adoption of enterprise resource planning (ERP) on cloud among small and medium enterprises (SMES) in Penang, Malaysia. J. Appl. Inf. Technol. 2016, 88, 398-409.

13. Valdebenito, J.; Quelopana, A. Conceptual Model for Software as a Service (SaaS) Enterprise Resource Planning (ERP) Systems Adoption in Small and Medium Sized Enterprises (SMEs) Using the Technology-OrganizationEnvironment (T-O-E) Framework. In Proceedings of the Advances in Intelligent Systems and Computing; Springer Science and Business Media LLC: Cham, Switzerland, 2019; pp. 143-152.

14. Oliveira, T.; Thomas, M.; Espadanal, M. Assessing the determinants of cloud computing adoption: An analysis of the manufacturing and services sectors. Inf. Manag. 2014, 51, 497-510. [CrossRef]

15. Salum, K.H.; Rozan, M.Z.A. Exploring the challenge impacted SMES to adopt cloud ERP. Indian J. Sci. Technol. 2016, 9, 1-9. [CrossRef]

16. Low, C.; Chen, Y.; Wu, M. Understanding the determinants of cloud computing adoption. Ind. Manag. Data Syst. 2011, 111, 1006-1023. [CrossRef]

17. Premkumar, G. A meta-analysis of research on information technology implementation in small business. J. Organ. Comput. Electron. Commer. 2003, 13, 91-121. [CrossRef]

18. Premkumar, G.; Ramamurthy, K. The role of interorganizational and organizational factors on the decision mode for adoption of interorganizational systems. Decis. Sci. 1995, 26, 303-336. [CrossRef]

19. Elbeltagi, I.; Al Sharji, Y.; Hardaker, G.; Elsetouhi, A. The role of the owner-manager in SMEs' adoption of information and communication technology in the United Arab Emirates. J. Glob. Inf. Manag. 2013, 21, $23-50$. [CrossRef]

20. Jeyaraj, A.; Rottman, J.W.; Lacity, M.C. A review of the predictors, linkages, and biases in IT innovation adoption research. J. Inf. Technol. 2006, 21, 1-23. [CrossRef]

21. Peng, G.C.A.; Gala, C. Cloud erp: A new dilemma to modern organisations? J. Comput. Inf. Syst. 2014, 54, 22-30. [CrossRef]

22. Faasen, J.; Seymour, L.F.; Schuler, J. SaaS ERP Adoption Intent: Explaining the South African SME Perspective. In Lecture Notes in Business Information Processing; Springer Science and Business Media LLC: Berlin/Heidelberg, Germany, 2013; Volume 139, pp. 35-47.

23. Demi, S.; Haddara, M. Do cloud ERP systems retire? An ERP lifecycle perspective. Procedia Comput. Sci. 2018, 138, 587-594. [CrossRef]

24. Lim, J.S.; Oh, J.I. A study on the effect of the introduction characteristics of cloud computing services on the performance expectancy and the intention to use: From the perspective of the innovation diffusion theory. Asia Pac. J. Inf. Syst. 2012, 22, 100-124.

25. Mijač, M.; Picek, R.; Stapić, Z. Cloud ERP System Customization Challenges. In Proceedings of the 24th Central European Conference on Information and Intelligent Systems, Varazdin, Croatia, 18-20 September 2013; pp. 132-140.

26. Lee, K.-P. Where would you build your big data analytics platform?-Comparative analysis between cloud and on-premise. J. Res. Methodol. 2018, 3, 101-117. [CrossRef] 
27. Elbahri, F.M.; Al-Sanjary, O.I.; Ali, M.A.M.; Naif, Z.A.; Ibrahim, O.A.; Mohammed, M.N. Difference comparison of SAP, Oracle, and Microsoft solutions based on cloud ERP systems: A review. In Proceedings of the 2019 IEEE 15th International Colloquium on Signal Processing \& Its Applications (CSPA), Penang, Malaysia, Malaysia, 8-9 March 2019; pp. 65-70. [CrossRef]

28. Grabski, S.V.; Leech, S.A.; Schmidt, P.J. A review of ERP research: A future agenda for accounting information systems. J. Inf. Syst. 2011, 25, 37-78. [CrossRef]

29. Arnesen, S. Is a cloud ERP solution right for you? Strateg. Finance 2013, 94, 45-50.

30. Mezghani, K. Switching toward cloud ERP. Int. J. Enterp. Inf. Syst. 2014, 10, 46-61. [CrossRef]

31. Gupta, S.; Meissonier, R.; Drave, V.A.; Roubaud, D. Examining the impact of cloud ERP on sustainable performance: A dynamic capability view. Int. J. Inf. Manag. 2020, 51, 102028. [CrossRef]

32. Ngai, E.W.; Law, C.; Wat, F. Examining the critical success factors in the adoption of enterprise resource planning. Comput. Ind. 2008, 59, 548-564. [CrossRef]

33. Bharadwaj, S.S.; Lal, P.; Lal, P. Exploring the Impact of Cloud Computing Adoption on Organizational Flexibility: A Client Perspective. In Proceedings of the 2012 International Conference on Cloud Computing Technologies, Applications and Management (ICCCTAM), Dubai, UAE, 8-10 December 2012; Institute of Electrical and Electronics Engineers (IEEE): Piscataway, NJ, USA; pp. 121-131.

34. Bellamy, M.C. Cloud Computing in the Large Scale Organisation Potential Benefits and Overcoming Barriers to Deployment. Ph.D. Thesis, Imperial College London, London, UK, 2014.

35. Chang, Y.-W. What drives organizations to switch to cloud ERP systems? The impacts of enablers and inhibitors. J. Enterp. Inf. Manag. 2020, 33, 600-626. [CrossRef]

36. Sahin, N.Y. Cloud ERP Security: Guidelines for Evaluation. Master's Thesis, Stockholm University, Stockholm, Sweden, 2013.

37. Weng, F. Competition and challenge on adopting cloud ERP. Int. J. Innov. Manag. Technol. 2014, 5, 309-313. [CrossRef]

38. Johansson, B.; Alajbegovic, A.; Alexopoulo, V.; Desalermos, A. Cloud ERP Adoption Opportunities and Concerns: The Role of Organizational Size. In Proceedings of the 2015 48th Hawaii International Conference on System Sciences, Kauai, HI, USA, 5-8 January 2015; Institute of Electrical and Electronics Engineers (IEEE): Piscataway, NJ, USA, 2015; pp. 4211-4219.

39. Ongowarsito, H.; Ekawati, A.D. Cloud EPR Adoption Factors in Large Companies. In Proceedings of the 2019 International Conference on Information Management and Technology (ICIMTech), Jakarta/Bali, Indonesia, 19-20 August 2019; Institute of Electrical and Electronics Engineers (IEEE): Piscataway, NJ, USA, 2019; Volume 1, pp. 230-233.

40. Tornatzky, L.G.; Fleischer, M.; Chakrabarti, A.K. Processes of Technological Innovation; Lexington Books: Lanham, MD, USA, 1990.

41. Priyadarshinee, P.; Raut, R.D.; Jha, M.K.; Gardas, B.B. Understanding and predicting the determinants of cloud computing adoption: A two staged hybrid SEM-Neural networks approach. Comput. Hum. Behav. 2017, 76, 341-362. [CrossRef]

42. Sohaib, O.; Naderpour, M. Decision Making on Adoption of Cloud Computing in E-commerce Using Fuzzy Topsis. In Proceedings of the 2017 IEEE International Conference on Fuzzy Systems (FUZZ-IEEE), Naples, Italy, 9-12 July 2017; Institute of Electrical and Electronics Engineers (IEEE): Piscataway, NJ, USA, 2017; pp. 1-6.

43. Juiz, C.; Gómez, B.; Bermejo, B.; Cordero, D.; Mory, A. A Guide for Cascading and Scaling up Green IT Governance Indicators through Balanced Scorecards: The Case of Data center Consolidation; Springer Science and Business Media LLC: Berlin/Heidelberg, Germany, 2019; pp. 133-142.

44. Rogers, E.M. Innovation in organizations. In Diffusion of Inovations; The Free Press: New York, NY, USA, 1995; Volume 4.

45. Tornatzky, L.G.; Klein, K.J. Innovation characteristics and innovation adoption-implementation: A metaanalysis of findings. IEEE Trans. Eng. Manag. 1982, 28-45. [CrossRef]

46. Shin, W.; Ahn, H. Effects of innovation characteristics of cloud computing services, technostress on innovation resistance and acceptance intention: Focused on public sector. Knowl. Manag. Res. 2019, 20, 59-86. [CrossRef]

47. Ram, S. A model of Innovation Resistance. In NA-Advances in Consumer Research; Melanie, W., Paul, A., Eds.; Association for Consumer Research: Provo, UT, USA, 1987; Volume 14, pp. 208-212. 
48. Ram, S. Successful innovation using strategies to reduce consumer resistance an empirical test. J. Prod. Innov. Manag. 1989, 6, 20-34. [CrossRef]

49. Yoo, P.-H.; Lee, S.-H. A study on the innovation resistance of consumers in adoption process of new product-concentrated on innovation resistance model. Korean Manag. Rev. 1994, 23, 32.

50. Benlian, A.; Hess, T. Opportunities and risks of software-as-a-service: Findings from a survey of IT executives. Decis. Support Syst. 2011, 52, 232-246. [CrossRef]

51. Kim, S. The Effect of Consumers' Innovation Resistance to FinTech Service on Intention to Recommend. Ph.D. Thesis, Kangwon National University, Gangwon-do, Korea, 2018.

52. Marston, S.; Li, Z.; Bandyopadhyay, S.; Zhang, J.; Ghalsasi, A. Cloud computing-The business perspective. Decis. Support Syst. 2011, 51, 176-189. [CrossRef]

53. Lutovac, M.; Manojlov, D. The successful methodology for enterprise resource planning (ERP) implementation. J. Mod. Acc. Audit. 2012, 8, 1838-1847.

54. Abdullah, N.H.; Shamsuddin, A.; Wahab, E.; Hamid, N.A. Preliminary qualitative findings on technology adoption of Malaysian SMEs. In Proceedings of the 2012 IEEE Colloquium on Humanities, Science and Engineering (CHUSER), Kota Kinabalu, Sabah, Malaysia, 3-4 December 2012; Institute of Electrical and Electronics Engineers (IEEE): Piscataway, NJ, USA, 2012; pp. 15-20.

55. Duan, Y.; Mullins, R.; Hamblin, D.; Stanek, S.; Sroka, H.; Cruz-Machado, V.; Araújo, J.P. Addressing ICTs skill challenges in SMEs: Insights from three country investigations. J. Eur. Ind. Train. 2002, 26, 430-441. [CrossRef]

56. Al-Jabri, I.; Roztocki, N. Adoption of ERP systems: Does information transparency matter? Telemat. Inform. 2015, 32, 300-310. [CrossRef]

57. Ram, J.; Corkindale, D.; Wu, M.-L. Implementation critical success factors (CSFs) for ERP: Do they contribute to implementation success and post-implementation performance? Int. J. Prod. Econ. 2013, 144, 157-174. [CrossRef]

58. Romm, T.; Pliskin, N.; Weber, Y.; Lee, A.S. Identifying organizational culture clash in MIS implementation. Inf. Manag. 1991, 21, 99-109. [CrossRef]

59. Son, I.; Lee, D. Assessing A New IT Service Model, Cloud Computing. In Proceedings of the PACIS, Brisbane, Australia, 7-11 July 2011; PACIS: Budapest, Hungary, 2011; pp. 179-188.

60. Jones, M.C.; Cline, M.; Ryan, S.D. Exploring knowledge sharing in ERP implementation: An organizational culture framework. Decis. Support Syst. 2006, 41, 411-434. [CrossRef]

61. Ke, W.; Wei, K.K. Organizational culture and leadership in ERP implementation. Decis. Support Syst. 2008, 45, 208-218. [CrossRef]

62. Nah, F.F.-H.; Zuckweiler, K.M.; Lau, J.L.-S. ERP implementation: Chief information officers' perceptions of critical success factors. Int. J. Hum. Comput. Interact. 2003, 16, 5-22. [CrossRef]

63. Holland, C.P.; Light, B. A critical success factors model for ERP implementation. IEEE Softw. 1999, 16, 30-36. [CrossRef]

64. Saeed, I.; Juell-Skielse, G.; Uppström, E. Cloud enterprise resource planning adoption. Adv. Enterp. Inf. Syst. 2012, 429-434. [CrossRef]

65. Lechesa, M.; Seymour, L.F.; Schuler, J. ERP Software as Service (SaaS): Factors Affecting Adoption in South Africa. In Lecture Notes in Business Information Processing; Springer Science and Business Media LLC: Berlin/Heidelberg, Germany, 2012; Volume 105, pp. 152-167.

66. Appandairajan, P.; Khan, N.Z.A.; Madiajagan, M. ERP on Cloud: Implementation Strategies and Challenges. In Proceedings of the 2012 International Conference on Cloud Computing Technologies, Applications and Management (ICCCTAM), Dubai, UAE, 8-10 December 2012; Institute of Electrical and Electronics Engineers (IEEE): Piscataway, NJ, USA, 2012; pp. 56-59.

67. Amini, M.; Sadat Safavi, N.; Mirzaeyan Bahnamiri, R.; Mirzaei Omran, M.; Amini, M. Development of an instrument for assessing the impact of environmental context on adoption of cloud computing for small and medium enterprises. Aust. J. Basic Appl. Sci. 2014, 8, 129-135.

68. Li, Y.-H. An empirical investigation on the determinants of e-procurement adoption in Chinese manufacturing enterprises. In Proceedings of the 2008 International Conference on Management Science and Engineering 15th Annual Conference Proceedings, Long Beach, CA, USA, 10-12 September 2008; Institute of Electrical and Electronics Engineers (IEEE): Piscataway, NJ, USA, 2008; pp. 32-37. 
69. Fan, Y.-W.; Chen, C.-D.; Wu, C.-C.; Fang, Y.-H. The effect of status quo bias on cloud system adoption. J. Comput. Inf. Syst. 2015, 55, 55-64. [CrossRef]

70. Rogers, E.M. Elements of diffusion. In Diffusion of Innovations; The Free Press: New York, NY, USA, $2003 ;$ p. 5.

71. Premkumar, G.; Roberts, M. Adoption of new information technologies in rural small businesses. Omega 1999, 27, 467-484. [CrossRef]

72. Gupta, S.; Misra, S.C.; Singh, A.; Kumar, V.; Kumar, U. Identification of challenges and their ranking in the implementation of cloud ERP. Int. J. Qual. Reliab. Manag. 2017, 34, 1056-1072. [CrossRef]

73. Salim, S.A.; Sedera, D.; Sawang, S.E.; Alarifi, A.H.; Atapattu, M. Moving from evaluation to trial: How do SMEs start adopting cloud ERP? Australas. J. Inf. Syst. 2015, 19. [CrossRef]

74. Martins, C.B.; Steil, A.V.; Todesco, J.L. Factors influencing the adoption of the internet as a teaching tool at foreign language schools. Comput. Educ. 2004, 42, 353-374. [CrossRef]

75. Fichman, R.G.; Kemerer, C.F. Adoption of software engineering process innovations: The case of object orientation. Sloan Manag. Rev. 1993, 34, 7.

76. Peng, G.C.; Nunes, M.B. Surfacing ERP exploitation risks through a risk ontology. Ind. Manag. Data Syst. 2009, 109, 926-942. [CrossRef]

77. Saa, P.; Moscoso-Zea, O.; Costales, A.C.; Luján-Mora, S. Data Security Issues in Cloud-Based Software-as-a-Service ERP. In Proceedings of the 2017 12th Iberian Conference on Information Systems and Technologies (CISTI), Lisbon, Portugal, 14-17 June 2017; Institute of Electrical and Electronics Engineers (IEEE): Piscataway, NJ, USA, 2017; pp. 1-7.

78. Pan, K.; Nunes, M.B.; Peng, G.C. Risks affecting ERP post-implementation. J. Manuf. Technol. Manag. 2011, 22, 107-130. [CrossRef]

79. Dutta, A.; Peng, G.C.A.; Choudhary, A. risks in enterprise cloud computing: The perspective of it experts. J. Comput. Inf. Syst. 2013, 53, 39-48. [CrossRef]

80. Eliasson, L.; Berg, S.; Sandberg, D. Some aspects on the more efficient use of wood in the industrial manufacture of single-fammily timber houses. Pro Ligno 2015, 11, 418-425.

81. Opara-Martins, J. A Decision Framework to Mitigate Vendor Lock-in Risks in Cloud (SaaS Category) Migration. Ph.D. Thesis, Bournemouth University, Poole, UK, 2017.

82. Kim, W.; Kim, S.D.; Lee, E.; Lee, S. Adoption Issues for Cloud Computing. In Proceedings of the 7th International Conference on Advanced in Mobile Computing and Multimedia, Kuala Lumpur, Malaysia, 14-16 December 2009; Association for Computing Machinery (ACM): New York, NY, USA, 2009; pp. 2-5.

83. Ali, A.Q.; Sultan, A.B.M.; Ghani, A.A.A.; Zulzalil,H. Empirical studies on the impact of software customization on quality attributes: A systematic review. J. Theor. Appl. Inf. Technol. 2019, 97, 1747-1763.

84. Kwahk, K.Y. Statistical Data Analysis with SPSS; Chungram: Seoul, Korea, 2019.

85. Song, J. SPSS/AMOS Statistical Analysis Method Required for Thesis Preparation; 21c Book: Paju, Korea, 2015. 